\title{
A inclusão da agricultura familiar na agenda governamental do município de Ilhéus-BA
}

\section{Carlos Henrique Nascimento Oliveira ${ }^{1}$, Pedro Araujo Pietrafesa ${ }^{2}$ e Antonio Pasqualetto ${ }^{3}$}

\author{
1 PUC GO. E-mail: henrique.pesquisas@hotmail.com \\ 2 Professor PUC GO E-mail: pedro_pietrafesa@yahoo.com.br \\ 3 Professor PUC GO E-mail: pasqualetto@pucgoias.edu.br
}

RESUMO: Nos últimos anos, o município de Ilhéus-BA implementou políticas públicas voltadas para o desenvolvimento da agricultura familiar. Dado o contexto histórico e cultural do município, bem como as características dessas políticas, a implementação simultânea do PAA, do PNAE e da ATER significou mudanças na forma como são tomadas as decisões políticas. Ao envolver de forma efetiva nessa ação o poder público local, agentes sociais e pequenos produtores rurais, essas políticas públicas conseguiram o duplo efeito de incluir a agricultura familiar na agenda governamental e transformar a relação político-administrativa em torno desse segmento. Neste artigo buscou-se investigar a operacionalização desses programas entre os anos de 2013 e 2017. Estudos preliminares mostram que a execução simultânea desses programas é algo recente, e que a sua continuidade e o seu aperfeiçoamento podem trazer resultados positivos aos agricultores familiares e à comunidade local.

Palavras-chaves: Agricultura familiar. Gestão pública. Políticas públicas. Sociedade.

The inclusion of family agriculture in the governmental agenda of the municipality of IlheusBA

\begin{abstract}
In recent years, the municipality of Ilhéus has implemented public policies aimed at the development of family farming. Given the historical and cultural context of the municipality, as well as the characteristics of these policies, the simultaneous implementation of the PAA, the PNAE and the ATER means changes in the form and order in which political decisions are made. By effectively involving local government, various social agents and small rural producers, these public policies achieved the double effect of including family agriculture in the government agenda and transforming the political-administrative relationship around this segment. It was sought to investigate the implementation of these programs between the years of 2013 and 2017; Preliminary studies show that the simultaneous implementation of these programs is a recent development and can be beneficial to local farmers and the local community.
\end{abstract}

Keywords: Family agriculture. Public management. Public politics. Society.

\section{INTRODUÇÃO}

O objetivo desse artigo é investigar a implementação de políticas públicas para a agricultura familiar no município de Ilhéus. Supõe-se que a implementação simultânea do PAA, do PNAE e do ATER entre os anos de 2013 e 2017 aponta para a inclusão da agricultura familiar na agenda governamental desse município.

No período compreendido para a pesquisa, foram executados de forma simultânea 
em Ilhéus, pelo governo municipal, o Programa de Aquisição de Alimentos (PAA), o Programa Nacional de Alimentação Escolar (PNAE) e o Programa de Assistência Técnica e Extensão Rural (ATER).

A operacionalização desses programas envolve a participação de diversos agentes políticos: governo federal, estadual e municipal, associações e cooperativas, os produtores rurais, comerciantes, escolas e creches municipais. A mobilização desses agentes em torno desse segmento é algo novo no município.

Historicamente, a agricultura sempre teve um papel de destaque na economia de Ilhéus. Durante o período colonial do Brasil e, nos demais períodos políticos da nação, essa localidade buscou, sem sucesso, desenvolver os ciclos econômicos que estavam sendo explorados nacionalmente, a exemplo: Cana-de-açúcar, café e borracha.

No século XIX, no entanto, a introdução da lavoura de cacau na antiga Vila de São Jorge dos Ilhéus iria possibilitar as condições para a transformação na estrutura desse município. Durante mais de cem anos a monocultura do cacau foi responsável pela formação política, econômica e cultural do município.

Registro aqui esse momento histórico, a fim de observar dois aspectos: Primeiramente, o cacau, em grande parte, foi produzido por pequenos produtores, muitas vezes, utilizando a mão-de-obra familiar para tal. Em segundo lugar, a cadeia produtiva do cacau sempre dispôs de recursos e de políticas públicas para suas atividades.

Faço essa observação para evidenciar que nesse trabalho pretende-se estudar uma diversificada produção agrícola e pecuária que foi cultivada por pequenos produtores em llhéus e, que se desenvolveu nas propriedades rurais em paralelo a produção de cacau, que sempre foi a atividade principal.

Em decorrência da crise na lavoura cacaueira no final dos anos 1980, o município de llhéus teve enormes prejuízos econômicos que resultaram no agravamento das condições de vida de sua população, principalmente a rural. $\mathrm{O}$ desemprego, a favelização e a violência urbana e rural aumentaram drasticamente.

Passados três décadas desse acontecimento, percebe-se com a execução desses programas, uma ação do poder público local no sentido de incentivar e desenvolver esses produtores, que permaneceram estagnados durante todo o século XX. Pelo fato do seu ineditismo, essa ação indica mudanças nas relações políticas e sociais em torno desse público.

Pode-se dizer que política pública é "o campo do conhecimento que busca, ao mesmo tempo, colocar o governo em ação e/ou analisá-la e, quando necessário, propor mudanças no rumo ou curso das mesmas (SOUZA, 2006, p. 26). Entende-se, nesse contexto, que a implementação de uma política pública é antecedida pela análise das condições estruturais mediante a observação de aspectos sociais, econômicos e culturais do público envolvido na obtenção de resultados duradouros.

A forma como determinada sociedade está constituída influencia o alcance e a aplicação de políticas públicas, exigindo do poder público maior esforço na preparação e na condução dos processos. Enquanto ferramenta e, ao mesmo tempo, enquanto expressão da realidade, a política pública tem a capacidade de transformar a configuração de um dado conjunto.

Verifica-se que, no Brasil, ao longo do 
tempo, políticas públicas foram criadas visando beneficiar os agricultores familiares. As mesmas envolvem diferentes aspectos, que englobam o acesso a linhas de créditos - Programa Nacional de Fortalecimento da Agricultura Familiar (PRONAF), o apoio à comercialização de produtos PAA e PNAE e a Assistência Técnica e Extensão Rural (ATER).

Entre os anos de 2014 e 2017, quando o governo municipal fez as primeiras aquisições de alimentos por meio do PAA, foram comercializados com recursos do programa mais de três milhões de reais. Esses recursos, apesar de disponibilizados pela União desde o ano de 2003, não eram captados pelo município.

A despeito dos benefícios desses programas, somente há três anos deram-se as condições políticas e sociais para sua operacionalização conjunta no município. A tomada de consciência política do poder público local, o fortalecimento da representação dos agricultores familiar, a diversificação agrícola e a necessidade de obtenção de lucros nessa atividade tiveram influência nessa decisão.

Constata-se que a participação efetiva das famílias rurais no PAA e PNAE, de forma individualizada ou por meio de cooperativa ou associação, reflete um novo momento da organização social de pequenos agricultores do município de llhéus.

Para Cazella, Bonnal e Maluf (2009), a "multifuncionalidade" da agricultura significa um novo olhar sobre a agricultura familiar, pois permite analisar a interação entre famílias rurais e territórios na dinâmica de reprodução social, considerando os modos de vida das famílias na sua integridade, e não apenas seus componentes econômicos.

$\mathrm{O}$ trabalho está dividido em três seções.
Na primeira, é apresentada a área de realização do estudo, abordando aspectos econômicos e políticos. Posteriormente, discute-se a implementação do PAA, do PNAE e da ATER no município de llhéus entre os anos de 2013 e 2017 e, em seguida, apresenta-se alguns resultados.

\section{CARACTERIZAÇÃO DA ÁREA DE ESTUDO}

O município de Ilhéus possui 184.236 habitantes (INSTITUTO BRASILEIRO DE GEOGRAFIA E ESTATIÍSTICA - IBGE, 2010) e está localizado no sul do estado da Bahia, na Microrregião Ilhéus-Itabuna. A Figura 1 mostra a localização do município:

Figura 1 - Localização do município de Ilhéus. Fonte: Instituto Nossa Ilhéus, 2016.

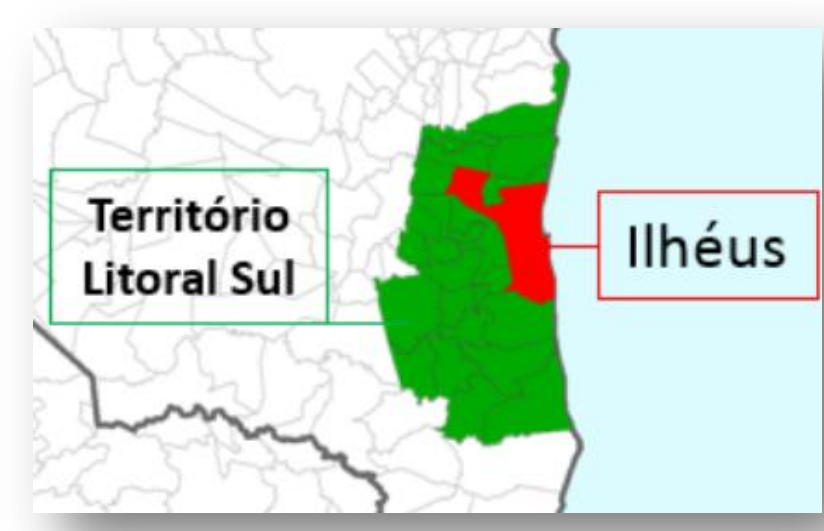

Ilhéus possui 3.346 propriedades rurais, que estão distribuídas em $1.584 .693 \mathrm{~km}^{2}$ (IBGE, 2010). A predominância de pequenas propriedades indica a inexistência de latifúndios contíguos nesse município. A Figura 2 apresenta a distribuição percentual do tamanho das unidades rurais: 
Figura 2 - Tamanho das propriedades rurais no município de Ilhéus (ha). Fonte: Adaptado pelo autor de IBGE, 2016.

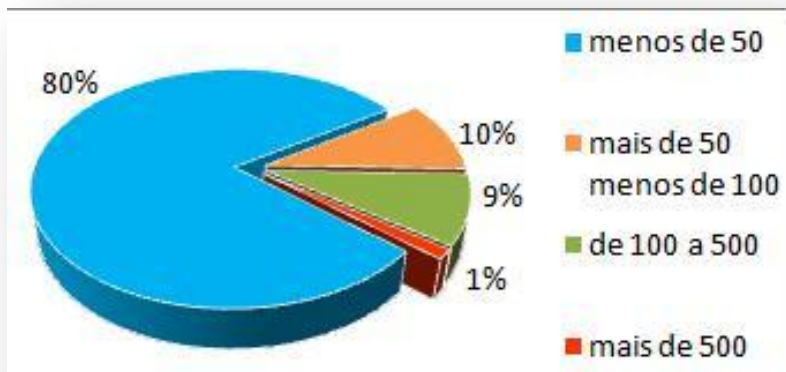

A presente pesquisa foi realizada no período de janeiro a junho de 2017 através da realização de entrevistas com membros do governo municipal, representantes dos produtores e de entidades relacionadas com a atividade. Como essa ação é atual, há ampla disponibilidade de evidencias empírica, assim, utilizou-se como fonte publicações em jornais, revistas e sites institucionais do município.

Buscou-se analisar comparativamente a outros períodos a estrutura atual do município no atendimento às necessidades do público alvo da pesquisa. Sabe-se, que historicamente, devido à desassistência institucional, esse público tem dificuldades técnicas e operacionais para produzir e comercializar seus produtos.

Sendo assim, foram observadas as condições das estradas vicinais, o suporte técnico para o plantio, se houve incremento de renda e lucro na atividade, a qualificação e a representação dos produtores rurais e a organização e condições do poder municipal para a execução dos programas.

A análise dessa estrutura nos dará subsidio para avaliar se a ação política empreendida até o momento, essa mobilização entre poder público e comunidade, permite afirmar, se, de fato, esse público foi incluso, mesmo que momentaneamente, na agenda política desse município.

Do ponto de vista institucional, é importante acrescentar que o município viveu durante todo o século XX sob o domínio político dos coronéis do cacau. Amado (1999) afirma que o coronel era um título que superava todos os demais, pois ele detinha o poder econômico e político na Região, e como tal, tinha o reconhecimento de superioridade e autoridade; situação que perdurou até os anos 1980.

Essa situação dificultou ao meio social de ilhéus a construção de um círculo virtuoso democrático, pois impossibilitou ao poder público local o exercício pleno de suas funções e, a comunidade, a efetividade de sua ação social.

No entanto, não é objetivo desse trabaIho aprofundar a análise para identificar se existe uma nova consciência nas relações políticas no município. Apesar da alternância de poder ser uma ameaça a continuidade dos programas, pretende-se focar o estudo na análise na pertinência da ação na opinião das partes envolvidas no processo.

Territorialmente, Ilhéus é constituído por distritos, vilas e povoados. Existe um distrito urbano, representado pela sede do município, e oito distritos rurais, onde estão distribuídos 11 vilas e 28 povoados (PREFEITURA DE ILHÉUS, 2017).

A distância geográfica de vilas e povoados da sede municipal dificulta a realização de serviços públicos e a implementação de políticas públicas, uma vez que alguns deles estão distantes $100 \mathrm{~km}$ da sede do governo, como é o caso das vilas de Inema, Pimenteira e Banco Central.

Referindo-se a tal situação, Angelito Dias Filho, atual Secretário de Agricultura e Pesca do município de Ilhéus (Secretaria Muni- 
cipal de Comunicação Social da Prefeitura de Ilhéus - SECOM), fez as seguintes declarações:

A malha rural de llhéus é complexa e extensa. São cerca de 1200 quilômetros de estradas vicinais [...]. A Secretaria de Agricultura e Pesca já recuperou, com recursos próprios, mais de $150 \mathrm{~km}$ de estradas rurais, consideradas estratégicas para o escoamento da produção do campo dos pequenos agricultores de llhéus. Hoje, homens e máquinas já estão recuperando as extensões das estradas vicinais do Assentamento João Amazonas e de acesso a localidade agrícola de Rio do Braço. No dia 05/06/2017, as atividades de recuperação vão chegar à região do Japu. Agora em junho, no entanto, as chuvas acontecem em maior proporção e com mais regularidade; isso, naturalmente, ocasiona maior desgaste das estradas vicinais [...]. Sendo assim, o programa de recuperação só pode ser sequenciado quando forem restabelecidas as condições climáticas favoráveis para procedimentos de terraplenagem e uso de máquinas pesadas (PREFEITURA DE ILHÉUS, 2017, s. p.).

Enquanto existia a riqueza advinda da produção de cacau, os produtores resolviam individualmente esses problemas. Além de suas riquezas pessoais, dispunham de apoio institucional do Instituto de Cacau da Bahia (ICB) e da Comissão Executiva do Plano da Lavoura Cacaueira (CEPLAC).

À medida que incorpora novas funcionalidades, o poder municipal se apropria do território e consolida sua institucionalidade. A ampliação de serviços na zona rural e a implementação de políticas públicas na agricultura familiar é um reflexo da integração desse poder aos segmentos socioeco- nômicos, sem a mediação da cadeia cacaueira.

Dado seu contexto histórico e social, a implementação do PAA, do PNAE e da ATER em Ilhéus representa o aperfeiçoamento das funções públicas desse poder na região. Ainda que tardiamente, a ocupação desse espaço pelo poder municipal significa a identificação de seu papel e da sua importância para o fortalecimento socioeconômico do município.

\section{A IMPLEMENTAÇÃO DE PROGRAMAS DA AGRICULTURA FAMILIAR NO MUNICÍPIO DE ILHÉUS}

Segundo Vivas Costa (2016), o programa de aquisição de alimentos foi executado na modalidade compra direta, e teve início no ano de 2014 com o cadastramento de 62 famílias de pequenos produtores. Em 2015, o número de famílias cadastradas subiu para 308.

O governo municipal foi a Unidade Executora do PAA, ficando responsável pela condução do Convênio junto ao Ministério do Desenvolvimento Social e Agrário, pelo cadastramento dos agricultores, pela recepção dos produtos e pela distribuição dos alimentos às entidades e instituições sociais do município (MDS, 2016).

Ainda de acordo com Vivas Costa (2016), entre 2014 e 2016 as aquisições realizadas no PAA somaram $R \$ 2.000 .000,00$. Os produtos mais comercializados foram: banana, abóbora, farinha, feijão, jiló, limão, mamão, milho verde e beiju, além de pescados, a exemplo de camarão, mariscos e peixes. $\mathrm{Na}$ Tabela 1, são apresentadas as quantidades comercializadas entre os anos de 2014 e 2016. 
Tabela 1 - Quantidade de produtos comercializados no município de Ilhéus entre anos de 2014 e 2016 no Programa de Aquisição de Alimentos. Fonte: Prefeitura de Ilhéus, 2016.

\begin{tabular}{cc}
\hline Produtos Comercializados & Quantidade (T) \\
\hline Abóbora & 4 \\
Aipim & 30 \\
Banana da prata & 50 \\
Banana da terra & 30 \\
Feijão & 3 \\
Hortaliças & 10 \\
Mamão & 1 \\
Pescados & 1 \\
\hline
\end{tabular}

Apesar do PRONAF não ser o foco deste estudo, cabe ressaltar o significativo crescimento dos valores captados a partir de 2013, o que pode indicar uma correspondência com a execução do PAA e do PNAE, haja vista as melhorias nas condições para a produção e comercialização dos produtos. A Tabela 2 mostra a evolução na quantidade de contratos em instituições financeiras e de créditos captados por agricultores de Ilhéus nos últimos anos.

Tabela 2 - Volume de recursos do PRONAF aplicados na agricultura familiar no município de Ilhéus e no Estado da Bahia entre os anos de 2009 a 2015. Fonte: MDA, 2015.

\begin{tabular}{c|ccc|c}
\hline \multirow{2}{*}{ Safra } & \multicolumn{2}{|c|}{$\begin{array}{c}\text { Quantidade de } \\
\text { Contratos }\end{array}$} & \multicolumn{2}{c}{ Valor em R\$ } \\
\cline { 2 - 5 } & Ilhéus & Bahia & Ilhéus & Bahia \\
\hline $2009-2010$ & 283 & 133.201 & 258.643 & 325.665 .155 \\
$2010-2011$ & 276 & 143.456 & 464.058 & 351.480 .225 \\
$2011-2012$ & 293 & 155.766 & 711.291 & 402.820 .683 \\
$2012-2013$ & 565 & 242.225 & 1.178 .727 & 694.784 .382 \\
$2013-2014$ & 431 & 217.415 & 1.399 .850 & 853.415 .060 \\
$2014-2015$ & 526 & 247.284 & 2.075 .563 & 923.187 .320 \\
\hline
\end{tabular}

No segundo semestre de 2016, a execução do PAA foi interrompida, sendo reativada somente após a transição política, quando a atual gestão municipal, que é oposição à gestão anterior, deu continuidade ao programa a partir do mês de abril de 2017.
Dias Filho (2017) esclarece que, para o ano de 2017, o programa conta com recursos da ordem de 976 mil reais, o que beneficiará 308 agricultores familiares e 21 entidades beneficentes de Ilhéus. "Chegamos a junho de 2017 com 52\% do programa cumprido, isso é um recorde no município" (DIAS FILHO, 2017, s. p.). O autor descreve um dos momentos da recepção dos alimentos:

Da longínqua localidade do Valão, ponto final da região agrícola do Itariri, onde residem e produzem no campo 35 famílias de pequenos agricultores, recebemos no dia 31/05/2017 polpa de Açaí e de Cupuaçu, além de uma grande quantidade de quiabo e abóbora. Esses produtosvão reforçar a mesa das creches, asilos e associações comunitárias selecionados pelo Conselho Municipal de Assistência Social (CHAME, 2017, s. p.).

Acerca do programa, Rita dos Santos, presidente da Associação dos Pequenos Agricultores e Moradores da Região de Maria Jape, afirmou que:

Durante muitos anos acompanhei meus pais quando eles comercializavam a pequena produção na extinta feira da Avenida Dois de Julho ${ }^{1}$.Era um tempo difícil, eles produziam pouco e não existia uma expectativa de venda. Hoje, temos a parceria com a Prefeitura de Ilhéus, que adquire boa parte da safra produzida pela comunidade através do PAA (CHAME, 2017, s. p.).

1 Localizada na antiga zona portuária, no centro de IIhéus, a Feira da Avenida Dois de Julho foi desativada nos anos 1980 e transferida para a Central de Abastecimento no Bairro do Malhado, que se constitui no principal centro de comercialização de alimentos no município. 
Para o agricultor Durvaci Alves, que participou pela primeira vez do programa, essa foi a melhor fase dos últimos anos: "Estava acostumado a uma perda de $30 \%$ das frutas e verduras por falta de comprador" (CHA$\mathrm{ME}, 2017$, s. p.). Em entrevista, ele afirmou que comercializava sua produção apenas nas feiras livres de llhéus.

Membro da Associação dos Pequenos Produtores de Búzios, zona sul de Ilhéus, João Celestino, de 57 anos, relatou que enfrenta diariamente as dificuldades no escoamento da sua produção, em função das condições da BR 251, trecho IlhéusBuerarema. Sobre essa situação ele ponderou que:

Nem todo dia os ônibus conseguem trafegar pela região; a banana é uma fruta que se estraga facilmente, perco muito dinheiro, cerca de 20 por cento do que produzo por falta de comprador. A inclusão de meu nome na lista dos fornecedores do PAA vai muito além do que diminuir o prejuízo. Passo finalmente a lucrar (PREFEITURA DE ILHÉUS, 2017, s. p.).

Presente ao evento de lançamento do PAA no município, no dia 06 de junho de 2017, o atual prefeito municipal, Sr. Mario Alexandre, disse conhecer de perto as necessidades da zona rural de Ilhéus. Referindo-se à implementação do programa de aquisição de alimentos, ele fez a seguinte análise:

Trata-se da valorização do homem e da mulher do campo e, também, do reconhecimento de sua importância para a economia do município. Mas é, também, um gesto solidário e de reconhecimento às entidades que, mesmo diante dos parcos recursos que dispõem para a sua ma- nutenção, se dedicam ao próximo, aos que mais precisam (PREFEITURA DE ILHÉUS, 2017, s. p.).

O PNAE é operacionalizado no município pela SEDUC, que tem a incumbência de montar o cardápio alimentar e orientar o processo licitatório. Entre os anos de 2014 e 2016 foram realizadas três licitações para o atendimento de 20.500 alunos distribuídos nas 117 escolas municipais. Na Tabela 3, constam os valores licitados.

Tabela 3 - Valores Licitados para o PNAE no município de Ilhéus entre os anos de 2014 e 2017. Fonte: Prefeitura de Ilhéus, 2017.

\begin{tabular}{ccc}
\hline Chamada Pública & Data Publicação & Valor (R\$) \\
\hline $01 / 2015$ & $11 / 04 / 2015$ & $633.222,20$ \\
$40 / 2015$ & $09 / 06 / 2015$ & $2.051 .777,22$ \\
$37 / 2016$ & $22 / 06 / 2016$ & $1.641 .161,26$ \\
$18 / 2017$ & $31 / 03 / 2017$ & $4.040 .747,45$ \\
\hline
\end{tabular}

A cooperativa de serviços sustentáveis da Bahia (COOPESSBA), com sede em Ilhéus, durante os anos de 2013 a 2016, foi a principal fornecedora de alimentos ao PNAE. Carine Assunção, presidente da cooperativa, em entrevista concedida em 2017, ressaltou a importância do programa para os agricultores familiares: "Como a absorção dos alimentos pelo PNAE é grande, os agricultores se sentem confiantes para diversificar sua produção; a monocultura do cacau passou, e somos cientes que podemos ganhar muito mais com a diversidade" (ASSUNÇÃO, 2017, s. p.).

Segundo Assunção (2017), alguns aspectos precisam ser melhorados na execução do PNAE no município de Ilhéus, dentre eles os processos burocráticos entre entrega dos produtos e recebimento dos valores, que "são muito demorados". Segundo ela, "percebemos pouca agilidade e descaso dos 
funcionários públicos". De um modo geral, ela fez as seguintes observações sobre os programas:

As políticas públicas como o PNAE e PAA são de grande incentivo para o agricultor familiar. Os agricultores se sentem motivados a produzir mais, por ter a garantia da safra, com preço e quantidade. A gestão municipal anterior se mostrou apta e executou as políticas. Hoje temos o COMDERUPES (Conselho Municipal de Desenvolvimento Rural e Pesqueiro) ativo na cidade de llhéus, este qual atua de maneira plural, democrática e fiscal, que existe para não só apenas ajudar, mais também levar conhecimento e empoderar o campo. Diante disso, sobre a atuação da nova gestão de Ilhéus não podemos discernir sobre muitos mais, apenas dizer que sempre somos otimistas e que hoje com o conselho sentimos a sociedade civil também atuante no processo (ASSUNÇÃO, 2017, s. p.).

O Conselho Municipal de Desenvolvimento Rural e Pesqueiro Sustentável (COMDERUPES) foi instituído no ano de 2013, por meio da Lei no 3.689, sendo sancionado pelo prefeito municipal nesse mesmo ano. O Conselho é representado por associação de moradores, colônias de pescadores, pequenos agricultores, comunidades indígenas, assentados, dentre outros segmentos do interior.

Para o Sr. Dero Farias, presidente da Cooperativa de Agricultura Familiar do Sul da Bahia (COOFASULBA), o Conselho é: "[...] a voz do homem do campo. Todas as primeiras terças-feiras do mês o Conselho Rural de Ilhéus se reúne para ouvir as reivindicações, trocar experiências, apresentar inovações no campo e buscar soluções coletivas junto às autoridades políticas locais" (PREFEITURA DE ILHÉUS, 2017, s. p.).

\section{ALGUNS RESULTADOS}

As compras institucionais realizadas pelo município de llhéus, a partir do ano de 2014, por meio do PAA e do PNAE, tiveram, em pouco tempo, elevação significativa, chegando, em 2016, ao valor de R\$ 2.000.000,00, liberados no PAA, e ao valor de $\mathrm{R} \$ 1.133 .594,70$, liberados via PNAE.

Tradicionalmente, os pequenos agricultores do município comercializam seus produtos nas feiras da Central de Abastecimento do Malhado, da Central de Abastecimento do bairro Hernane Sá e na feira da Guanabara. Com a implementação pela prefeitura do PAA e do PNAE, abriu-se um canal importante para esses produtores, visto que tanto a produção como a comercialização são assistidas pelo poder público, por meio da ATER, promovendo a melhora na qualidade dos produtos, o aumento da renda e a diminuição dos riscos.

Em entrevistas realizadas com os produtores rurais, observa-se que as principais dificuldades para produzir e comercializar os produtos estão relacionadas com o acesso ao crédito, a assistência técnica, o transporte dos produtos da zona rural até as feiras, o preço dos produtos, e a dificuldade de sobreviver somente com a renda da terra.

A maioria dos produtores entrevistados reside na propriedade rural. Observou-se, no entanto, que, em todas as famílias dos produtores entrevistados, algum de seus membros trabalha com carteira assinada, principalmente no comércio e na indústria local.

Nota-se que a produção é desconcentra- 
da em vários produtos. Cada produtor planta e colhe pequenas quantidades de alimentos, que servem para sua subsistência e comercialização. Quase todos os entrevistados comercializam seus produtos em feiras do município.

Neste contexto, importa destacar que, no PAA, a prefeitura compra os produtos diretamente do produtor, de forma individualizada, e, no PNAE, até o ano de 2016 a compra ocorria na COOPESSBA, cooperativa que reúne agricultores familiares de Ilhéus e região.

\section{CONSIDERAÇÕES FINAIS}

Após a apresentação e a análise dos dados acerca das condições da agricultura familiar em llhéus, é possível apresentar algumas considerações.

O município de llhéus possui estrutura fundiária com predominância de pequenas propriedades; $80 \%$ delas têm até 50 hectares. Ressalta-se que o cacau ainda é a principal atividade agrícola, porém o município apresenta produção diversificada na agricultura, pecuária e pesca.

O melhor aproveitamento de áreas disponíveis para agricultura, mediante a utilização de técnicas e tecnologias adequadas, que possibilite ganhos econômicos, com formação de excedentes e a melhora da qualidade dos produtos, é um dos objetivos das políticas públicas para a agricultura familiar.

Dentro do tripé fomento, comercialização e assistência técnica, contemplados nas linhas PRONAF, PAA, PNAE e ATER, busca-se disponibilizar ao agricultor familiar as ferramentas necessárias ao seu desenvolvimento. No município de llhéus, verificou-se a implementação dessas políticas públicas pela administração municipal a partir do ano de 2013.

A realização simultânea desses programas, com a participação de variadas instituições - secretarias estaduais, prefeitura, instituições financeiras, associações, cooperativas e produtores - é, de fato, um ganho expressivo para a agricultura familiar no município, dado o ineditismo da ação.

Essa articulação institucional para o desenvolvimento da agricultura familiar marca também o rompimento com a tradição individualista verificada durante um século em torno da atividade cacaueira. Acerca desse período são recorrentes os relatos de insucesso das tentativas de se organizar a atividade dentro de uma visão associativista e cooperativista.

A gestão das propriedades rurais em IIhéus aliada à forma como se dão os processos de produção evidenciam o caráter tradicional das atividades agropecuárias no município. A baixa incorporação de progressos tecnológicos, a baixa produtividade, os reduzidos investimentos e sua vocação para a produção de matéria-prima denotam esse caráter histórico e persistente.

Sendo assim, o aparato tecnológico para uma guinada da produção agropecuária no município, com influência nos aspectos mercantil e econômico, passa pelo fortalecimento de associações de produtores, cooperativas, sindicatos rurais e por uma participação mais ativa do poder público local.

Essas instituições têm a capacidade de conduzir processos coletivos de gestão e inovação, além de reunir a produção local, dando-lhe maior poder de competitividade. Hoje, o alcance de comercialização dos pequenos produtores rurais do município restringe-se ao mercado local e regional, o que compromete a geração de renda e riqueza 
no meio rural do município.

Apesar dos avanços com a implementação do PAA, do PNAE e, em especial, da ATER, a permanência dos programas depende de motivação política, fato que impede projeções futuras quanto ao seu crescimento, principalmente em um contexto de alternância de poder.

$\mathrm{Na}$ agricultura familiar, a experiência de implementação desses programas em centros mais desenvolvidos, a exemplo da região Sul do país, mostra que essa fragilidade é superada por meio de coesão social, representação setorial consolidada e consciência coletiva. Verifica-se que as condições para tal mudança fazem-se presentes, a saber: autonomia, experiência, terra, clima favorável, mercado e capital disponível.

\section{REFERÊNCIAS}

AMADO, J. São Jorge dos Ilhéus. 52. ed. Rio de Janeiro: Record, 1999.

ASSUNÇÃO, C. Presidente da Cooperativa de Serviços Sustentáveis da Bahia. Disponível em: <http://coopessba@coopessba. com>. Acesso em: 08 mar. 2017.

CAZELLA, A. A.; BONNAL, P.; MALUF, R. F. Agricultura familiar: multifuncionalidade e desenvolvimento territorial no Brasil. Rio de Janeiro: Mauad X, 2009.

CHAME, R. R. Prefeito de Ilhéus destaca importância da aquisição e distribuição de alimentos da agricultura familiar. 2017. Disponível em: <http://www.r2cpress.com. br/v1/2017/05/31/prefeito-de-ilheus-desta ca-importancia-da-aquisicao-e-distribuicaode-alimentos-da-agricultura-familiar/>. Acesso em: 20 jun. 2017.

DIAS FILHO, A. Secretário Municipal de Agricultura e Pesca do município de Ilhéus. Disponível em: <http://www.ilheus.ba.gov. br/detalhe-da-materia/info/estradas-doassentamento-joao-amazonas-e--rio-dobraco-sao-recuperadas/59329>. Acesso em: 20 jun. 2017.

INSTITUTO BRASILEIRO DE GEOGRAFIA E ESTATÍSTICA. Mapas. 2010. Disponível em: <http://www.estatgeo.ibge.gov.br/mapa/m apa.html?nm6=1\&ni=6\&ui=2913606\&nz= $6 \& u z=2913606>$. Acesso em: 09 nov. 2016.

\section{Número de estabelecimentos e} área dos estabelecimentos agropecuários, por condição legal do produtor em relação às terras, sexo do produtor, grupos de atividade econômica e grupos de área total. 2016. Disponível em: <http://www.sidra.ib ge.gov.br/bda/tabela/listabl.asp?c=787\&u= $2491 \& z=t \& o=4 \& i=P>$. Acesso em: 08 nov. 2016.

INSTITUTO NOSSA ILHÉUS. Mapa território Ilhéus. 2016. Disponível em: http://www. nossailheus.org.br/nossa-ilheus/mapa-terri torio-ilheus/>. Acesso em: 11 nov. 2016. MINISTÉRIO DO DESENVOLVIMENTO SOCIAL E AGRÁRIO. Desenvolvimento Social. 2014. Disponível em: <http://mds.gov.br/>. Acesso em: 20 nov. 2016.

PREFEITURA DE ILHÉUS. Estradas do Assentamento João Amazonas e Rio do Braço são recuperadas. 2017. Disponível em: <http://www.ilheus.ba.gov.br/detalhe-damateria/info/estradas-do-assentamento-jo ao-amazonas-e--rio-do-braco-sao-recupera das/59329>. Acesso em: 20 jun. 2017.

\section{Prefeitura Municipal de Ilhéus.} 2016. Disponível em: http://www.ilheus.ba. gov.br/bus_ava.aspx?search=agricultura\%2 Ofamiliar>. Acesso em: 22 nov. 2016.

SECRETARIA ESPECIAL DE AGRICULTURA FAMILIAR E REFORMA AGRÁRIA. Agricultura familiar. 2016. Disponível em: <https:// www.mda.gov.br/>. Acesso em: 20 nov. 2016. 
PAA. 2016. Disponível em: <http://www.mda.gov.br/sitemda/secretari a/saf-paa/sobre-o-programa>. Acesso em: 20 nov. 2016.

\section{Plano Safra da Agricultura Familiar}

2016/2017. Disponível em: <http://www. mda.gov.br/sitemda/plano_safra>. Acesso em: 20 nov. 2016.

SOUZA, C. Políticas Públicas: uma revisão da literatura. Revista Sociologias, Porto Alegre, ano 8, n. 16, jul./dez. 2006.

VIVAS COSTA, S. A. Secretário Municipal de Agricultura e Pescado município de llhéus. 20216. Disponível em: http://www.ilheus. ba.gov.br/Materia_especifica/6500>. Acesso em: 10 nov. 2016.

Artigo recebido em 25 de setembro de 2017.

Aprovado em 29 de novembro de 2017. 